\title{
TyphicIleal Perforation at Kati Chu-BSS for Diagnostic and Therapeutic Aspects (Mali)
}

\section{Koniba Keita ${ }^{1 *}$, Abdoulaye Diarra ${ }^{1}$, Sidiki Keita ${ }^{2}$, Salia Coulibaly ${ }^{3}$, Oulematou Coulibaly ${ }^{4}$, Amadou Traoré5, Assitan Kone1, Oumou Koné1, Fodé Mory Keita6 ${ }^{6}$, Daouda Diallo7, Boubacar Kone1, Drissa Traoré6, Bacary T. Dembélé ${ }^{5}$}

\author{
${ }^{1}$ General Surgery Department, Hospital BSS, Kati, Mali \\ ${ }^{2}$ General Surgery “A” Department, Hospital Point-G, Bamako, Mali \\ ${ }^{3}$ Medical Imaging Department, Hospital BSS, Kati, Mali \\ ${ }^{4}$ Reference Heath Centre of the Commune VI, Bamako, Mali \\ ${ }^{5}$ General Surgery Department, Hospital Gabriel Touré, Bamako, Mali \\ ${ }^{6}$ General Surgery “B” Department, Hospital Point-G, Bamako, Mali \\ ${ }^{7}$ Anesthesia Resuscitation Department, Hospital BSS, Kati, Mali \\ Email: *konibakeita91@gmail.com
}

How to cite this paper: Keita, K., Diarra, A., Keita, S., Coulibaly, S., Coulibaly, O., Traoré, A., Kone, A., Koné, O., Keita, F.M., Diallo, D., Kone B., Traoré, D. and Dembélé, B.T. (2021) Typhiclleal Perforation at Kati Chu-BSS for Diagnostic and therapeutic aspects (Mali). Surgical Science, 12, 286-295. https://doi.org/10.4236/ss.2021.128029

Received: July 7, 2021

Accepted: August 23, 2021

Published: August 26, 2021

Copyright $\odot 2021$ by author(s) and Scientific Research Publishing Inc. This work is licensed under the Creative Commons Attribution-NonCommercial International License (CC BY-NC 4.0). http://creativecommons.org/licenses/by-nc/4.0/ (c) (i) (8) Open Access

\begin{abstract}
Ileal perforation of typhus origin is a common and serious complication of typhoid fever in tropical environments. It is one of the main causes of morbidity in surgery in Mali. However, it would be preventable if salmonellosis were properly managed upstream, and if our living environments were cleaned up. The purpose of this study is to report on the experience of the Kati UHC General Surgery Department in the management of peritonitis by typhic perforation and to assess its prognosis. Patients and Method: This is a retrospective descriptive study that took place from January 2007 to December 2020 in the General Surgery department of the Hospitalo-University BSS Center of Kati (Mali). We have included patients who have undergone peritonitis with confirmed typhic ileal perforation with laparotomy. The other etiologies of peritonitis by ileal perforation were not retained. Results: In 14 years, we collected 89 cases of peritonitis by typhic ileal perforation. It accounted for $3.14 \%$ (89/2829) of surgical procedures, $37.5 \%$ (89/1181) of visceral surgical emergencies and $27.6 \%(89 / 322)$ of all acute peritonitis causes combined. There were 70 men against 29 women; the sex ratio was 2.4 with an average age of 25.8 years (extremes 8 years to 65 years). Anastomosis resetions (ileo ileal and ileocolic) predominated in $71.8 \%$ of patients. However, the ileo stoma was performed in 5.6\%. A significant relationship ( $\mathrm{p} 0.05$ ) was observed between high mortality and MPI score $>26$. Morbidity was $39.4 \%$ with mortality of $15.7 \%$. The average length of stay in hospital was 12.2 days. Conclusion: Typhoid ileal perforation is common in young male adolescents
\end{abstract}


in visceral surgery. This pathology generates significant morbidity. However with the extension of hand washing after Ebola disease its frequency has dropped.

\section{Keywords}

Typhoid Perforation, Diagnostic, Surgery

\section{Introduction}

Typhoid perforation is defined as the opening of a hollow viscera in the abdominal cavity due to salmonella [1]. In most cases, this perforation occurs at the level of the terminal ileum or gallbladder. It is a serious complication of typhoid fever. Its frequency is high in African series [2] [3] however it is a pathology almost unknown in developed countries. Postoperative mortality remains high in sub-Saharan Africa, ranging from $14 \%$ to $29.3 \%$ [4] [5] mainly due to the late arrival of patients in health facilities. Through this study, we report our experience on the clinical and therapeutic aspects in the management of ileal perforations of typhic origin in the general surgery department of the CHU BSS of Kati.

\section{Patients and Method}

This is a mono-centric, cross-sectional descriptive and analytical retrospective study carried out over a ten-year period, from January 2007 to December 2020, in the General Surgery department of the CHU BSS in Kati.

The study covered all cases of perforationic or biliary peritonitis confirmed by clinical, paraclinical and intraoperative lesion findings. We did not include the ileal perforations of traumatic or ballistic origin and the other causes of acute peritonitis. The study parameters were the clinical signs of peritonitis, the notion of long-term fever, looking for a dissociation pulse temperature. The X-ray of the abdomen without preparation (ASP) was systematically requested in search of pneumoperitonene. However, abdominal ultrasound was not systematic. Serodiagnosis of Widal and Felix was routinely requested in post-operative patients. We evaluated the general state with the Karnofski index which varies from $10 \%$ to $100 \%$. The prognosis assessment was made with the Mannheim Peritonitis Index (MPI) score ranging from 0 to 47 points. All patients had pre-operative blood tests. Bacteriological cultures and the ionogram were not feasible in an emergency. All patients received pre, per and post-operative resuscitation under the supervision of a resuscitator. Probabilistic antibiotic therapy was based on injectable ceftriaxone, metronidazole perfusion, sometimes associated often with gentamycin. The presence of false membranes and the inflammatory aspect of the last ileal loop, the quantity pus in the peritoneal cavity. In addition, the surgical technique performed (ravivement-suture, anastomosis resection, ileo stoma), morbidity and mortality were evaluated. Data entry and analysis was performed on Microsoft Office Word 2007, SPSS version 17.0. The 
statistical comparison test was $\mathrm{Khi}^{2}$ with a P $0.05 \%$ risk considered statistically significant.

\section{Results}

We have collected 89 cases of peritonitis by ileal perforation of typhic origin for 14 years. It accounted for 3.14\% (89/2829) of surgical procedures, 7.5\% (89/1181) of visceral surgical emergencies and $27.6 \%$ (89/322) of all acute peritonitis.

Epidemiological aspects: the age group 0 - 20 years was the most represented $50 \%$; the average age was 25.8 years with extremes 8 and 65 years. There were 70 men against 29 women; the sex ratio was 2.4 or 70 men (78.7\%) against 29 women (21.3\%).

Consultation time: the average consultation time between the onset of symptoms and admission to hospital was 5.4 days with extremes of 2 to 14 days.

Clinical aspects: from a functional symptomatology point of view, abdominal pain was reported by $100 \%$ of patients, and food vomiting in $83 \%$ and the notion of stopping materials and gas in $20 \%$. From a general symptomatology point of view the Karnofski index was $70 \%$ for $84.6 \%$ of patients and fever in $98.5 \%$. Temperature pulse dissociation was observed in $27 \%$ of patients. Physical symptomatology was dominated by umbilic cry $100 \%$, abdominal contracture with matte in $85.6 \%$ (76 patients), abdominal defence14.4\%. The disappearance of prehepatic matter was noted in $64.04 \%$ (57/89). Painful rectal bulging was observed in $75 \%$ (67 patients). The additional examinations:

X-ray of the abdomen without preparation (ASP) was requested in $100 \%$ of our patients. It allowed to observe a gas crescent under diaphragmatic (pneumoperitoine) in $65 \%$ of patients. Hydro-aeric levels were observed in $30 \%$ of patients. Abdominal ultrasound was not systematic because once the clinical signs of acute peritonitis were positive with radiological signs, the patient was prepared for surgery. Noted that $20 \%$ of patients returned with their abdominal ultrasounds mentioning a purulent effusion in the abdominal cavity hence the interest of a surgical opinion. Biology: leukocytosis was observed in $100 \%$ of patients. Widal and Felix serodiagnosis was positive in $71.9 \%$ (43/60) of patients.

Blood culture and coproculture were not included in this study. Cytobacteriological examination of pus was not feasible urgently in our structure. The typhic etiological aspects by extension focused on the presence of perforation on the last ileal loop, with an inflammatory appearance of the terminal ileum bearing white false membranes. Therapeutic aspects: all patients (100\%) were operated under general anesthesia. They were managed by the resuscitating anesthesiologists before, during and after the surgery. Correction of hydro electrolyte imbalances (infusion of Ringer lactate, saline serum and glucosia) was systematic. Thirty patients (30) were transfused by iso group and iso rhesus blood. Xyphopubic laparotomy was performed in $95 \%$ (85/89) of patients and $5 \%$ of patients underweight umbilical surgery. The volume of purulent or seropurulent effusion ranged from 300 to 1700 millilitres. Effusion was faecal in 2 patients. Perfora- 
tions occurred in the last 20 centimetres $(\mathrm{cm})$ before the ileo-caecal junction in $83 \%(74 / 89)$ of patients, and before the last $20 \mathrm{~cm}$ in 17\% (15/89) of patients. Perforation was unique in 30\% (27 patients), double in 60\% (53 patients), multiple in $10 \%$ (9 patients). Extensive inflammation of the ileum covered with false whitish membranes, often with pre-perforative areas, was observed over the last 100 centimetres. Multiple small lymphadenopathies on the mesenteric edge of the ileum were observed. Peritoneal washing was done with saline saline saline ranging in volume from 3 to 5 litres. Multi-perforated tubular drains were used to drain the peritoneal cavity. Surgical actions were recorded in Table 1. Broad-spectrum probabilistic antibiotic therapy (injectable ceftriaxone or ciprofloxacin perfusion + metronidazole perfusion) was administered to J0-J5 patients. The relay was taken by a 3 rd generation cephalosporin or ciprofloxacin by the post-operative oral route. Ninety percent of patients were operated on before the 6th hour of hospital admission.

Early surgical follow-ups (J0 to J30) were simple in $44.9 \%$ of patients, compared to $57.4 \%$ morbidities dominated by parietal abscesses $39.3 \%$.

There was a significant relationship ( $\mathrm{p}$ 0.05) between significant morbidity and the MPI > 26 score.

The average length of hospitalization was 12.2 days with extremes were 5 and 67 days. Mortality was $15.7 \%$ (14/89) in patients.

\section{Discussion}

At the end of this study, we collected 89 patients files for typhic ileal perforation peritonitis surgery in 14 years. It accounted for 27.6\% (89/322) of all peritonites. This frequency is variously reported in African series, ranging from $14 \%$ to $67.9 \%$ [2] [6]. It is superimposed to the $29 \%$ of Togola [7] but superior to the $20 \%$ of Kambiré I [8]. On the other hand, the frequency of typhus perforations in this study is not comparable to that of Kassegné [2], which observed a frequency of $69.9 \%$. In rural areas. Generally, depending on whether the study is carried out in rural, semi-urban or urban areas, the frequencies vary from one country to another. The average age observed was 25.8 years with a sex ratio of 2.4. This age can be transposed to that of Sanogo Z.Z [9] who found an average age of 22.7. On the other hand, we cannot compare the average age in our study with that of Coulibaly Y [3] who had found an average age of 9.8 years. The study was conducted in a pediatric setting only. Generally speaking, in the African series [10] [11] it appears that typhic ileal perforations occur in children, adolescents and young adult males. This may be due to a lack of compliance with hygiene measures in this unit. In addition the female sex would be more inclined to observe hygiene measures than men. It should be noted that after the advent of Ebola disease in 2014 in Mali, the extension of hand washing has contributed enormously to the improvement of hygiene conditions in the country. As a result, we have seen a significant decrease in the frequency of typhic perforation peritonites in our structure (Figure 1). 


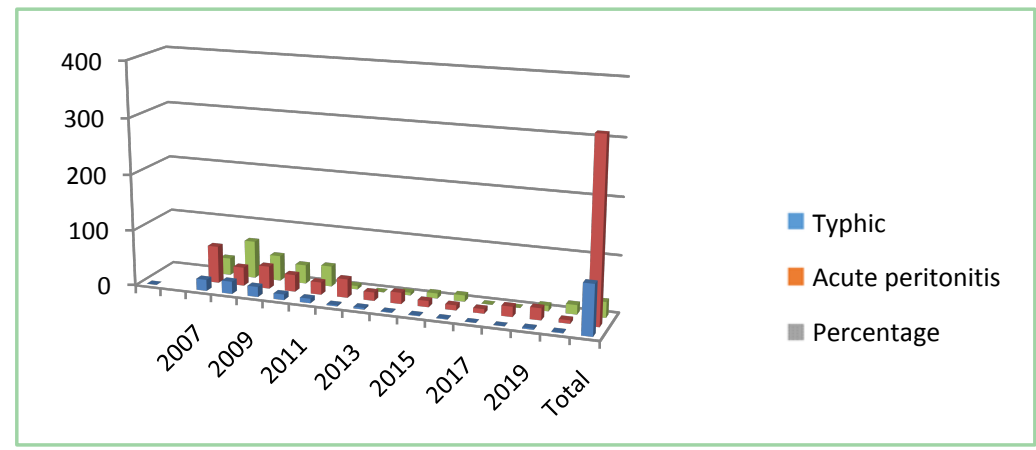

Figure 1. Distribution of typhus perforations per year.

Table 1. Follow-up procedures J0 to J30.

\begin{tabular}{cccc}
\hline Surgical follow-up & Frequency & Percentage & \\
\hline Singles & 40 & 44.9 & \\
Wall abscesses & 35 & 39.3 & \\
Digestive fistula & 6 & 6.7 & \\
Postoperative peritonitis & 1 & 1.1 & $57.4 \%$ \\
Peristomal irritation & 4 & 4.4 & \\
Evisceration & 5 & 5.9 & \\
Deaths & 14 & 15.7 & \\
\hline
\end{tabular}

Clinically, the notion of long-term fever for more than 14 days was observed in $85 \%$ of our patients. In its pathophysiology the complications of typhoid fever usually occur during the second seven years except in case of administration of high doses of antibiotics at the beginning of the disease; this could lead to a massive lysis of bacterium and release of high-dose endotoxin into the blood causing complications. Pulse and temperature dissociation was observed in $27 \%$ of patients. The presence of this sign in a feverish tropical setting is generally in favor of typhoid fever. Niangaly A, [5] had observed it in $12 \%$ of these patients. The symptomatic triad (umbilical call, vomiting, fever) observed in this study has been reported in the literature [9]; as well as abdominal defense and or contracture (wood matter) and rectal pain. Our study is superimposed on that of the African authors [9] [12]. The disappearance of prehepatic matter observed in 64, $04 \%$ of patients. This is a sign that is in favor of a perforation of a hollow organ of the digestive tract with gas leakage into the peritoneal cavity.

Additional tests, serodiagnosis of Widal and Felix were carried out in $67.4 \%$ $(60 / 89)$ of patients. It returned positive in $71 \%$ (43/60). Although it is no longer a reference examination, its positivity in a context of ileal perforation directly incriminates a typhic etiology. Its negativity has no pathological value. This examination was requested generally after surgery. Our results are similar to those of Niangali A [5] and Sanogo ZZ [9] which respectively found 74.1\% and $62.5 \%$. If Coulibaly M [12] observed $85.5 \%$ leukocytosis, in our study we observed it in $100 \%$. All our patients have been operated at the stage of extreme infectious complication (generalized acute peritonitis). We have not done blood cultures or co-productions in the context of patient poverty. The X-ray of the abdomen 
without preparation was performed in $100 \%$ of patients. Its sensitivity would vary from $50 \%$ to $70 \%$ in the literature [13]. It allowed to observe an image of pneumoperitoine in $65 \%$ of patients. It is a pathognomonic sign of perforation of a hollow organ of the digestive tract. This result is higher than that of Sanogo $\mathrm{ZZ}$ [9] which had observed $55.8 \%$ of pneumoperitoine, but close to $63.9 \%$ of Coulibaly M [12].

The average consultation time was 5.6 days. The patients arrived late in our structure between the 5th and 6th day of the worsening of the disease. This would be explained not only by self-medication, lack of financial means and traditherapy. This duration is variously reported in the literature; Kambiré JL [8], and Coulibaly Y [3] had observed 9, 8 days and 11.1 days respectively.

Therapeutic aspects: as reported by Sanogo ZZ [9] "patients are received in hospital in a state of physiological misery"; we made the same finding in our patients. They all underwent short resuscitation, intense and effective 2 to 3 hours before surgery. Double probabilistic ceftriaxone injectable or ciprofloxacin infusion antibiotic therapy associated with metronidazole infusion was administered to patients. This antibiotic therapy was continued in postoperative after 7 days. One hundred percent $(100 \%)$ of patients were operated on under general anesthesia. The median laparotomy above and below the umbilical was the first preferred route. If in developed countries the celeo surgery is the standard Gold for the management of peritonitis, in our countries, in Africa south of the Sahara, this technique is not well implanted in our structures. Surgical gestures were listed in Table 2. If suture excision was preferred in single perforations, but in multiples, the surgical option focused on anastomosis resection or ileo resection stoma according to the patient's stable or unstable hemodynamic state.

In our series anastomosis resections were the most performed surgical gesture $71.8 \%$. Sixty-two decimal nine per cent (62.9\%) for ileocolic anastomosis and $8.9 \%$ for ileum. Colic ileo anastomosis was performed in multiple perforations (Figure 2) that occurred in the last 20 to 30 centimetres of the ileo-caecal junction; or when the suspicious pre-perforative areas extended beyond these areas. This required us to resect the ileal segment to the healthy zone and proceed with anastomosis. The choice of this technique is related to the fact that anastomoses in the last ileal segment are sources of fistula frequently because of the poor vascularization of this area. On the other hand, when the perforations were beyond the last $40 \mathrm{~cm}$ of the caecal ileum junction, ileum anastomosis was preferred if the patient's overall hemodynamic condition allowed it. Otherwise it was the resection ileo stoma. The resection rate anastomosis varies in the African series from $5.2 \%$ to $40.5 \%$ [2] [4] [5] [9]. Their developments were favourable in $85 \%$ of cases, as reported by Ayité A [14]. The stoma ileo is difficult to manage in our countries. It not only aggravates the undernutrition of patients, in addition, they are poorly perceived psychologically by the patient and his entourage. The lack of stoma pouches and their high cost to our patients required the use of plastic pouches for stoma (Figure 3). Peristomial irritation was observed in $4.4 \%$ of patients. 
Table 2. Operating procedures.

\begin{tabular}{cccc}
\hline Operating techniques & Frequency & Percentage & \\
\hline Excision suture & 20 & 22.6 & \\
Ileocolic anastomosis resection & 56 & 62.9 & $71.8 \%$ \\
Ileal anastomosis resection & 8 & 8.9 & 5.6 \\
Resection ileo stoma & 5 & 100 & \\
Total & 89 & & \\
\hline
\end{tabular}

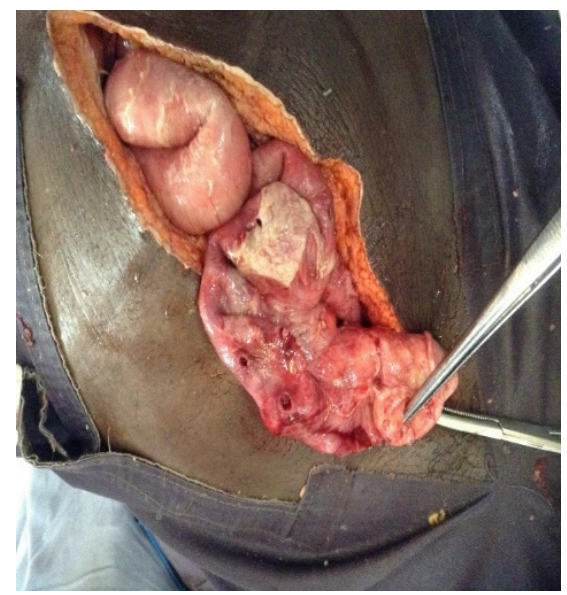

Figure 2. Multiple ileal perforation.

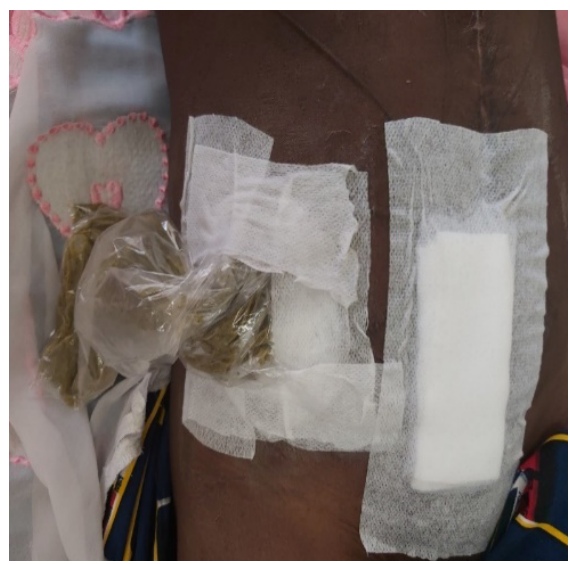

Figure 3. Plastic bag apparatus.

The surgical aftermath of the typhic ileal perforations were grafted with a significant morbidity $57.4 \%$. This could be explained by the type of surgery in the classification of Althémeir where peritonites are classified surgery room. The morbidity observed in this study is similar to that of Niangaly [5] and Ngo Nonga [15] who found $51.5 \%$ and $59.6 \%$ respectively. On the other hand, it is higher than $13.5 \%$ in the study of VIGNON Kc, [16] and lower than $72.2 \%$ observed in the study of Ouedrago [17]. Morbidities in the African series vary widely from study to study, depending on whether the study is in rural or urban settings. 
Table 3. Mannheim score and operative suites.

\begin{tabular}{ccccc}
\hline Mannheim Score & $\leq 26$ & $>26$ & Total & Statistical Test \\
\hline Single & 24 & 16 & 40 & \\
Complicated & 16 & 19 & 35 & 0.216 \\
Deaths & 1 & 13 & 14 & 0.0000 \\
Total & 41 & 48 & 89 & \\
\hline
\end{tabular}

$\mathrm{P}=0.0000$.

The mortality observed in our study was $15.7 \%$. It is superimposed on that of Allodé [4], Sanogo ZZ [9], and Coulibaly Y [3], who found respectively 14.5\%, $15.8 \%, 15.2 \%$. On the other hand, it was below $29.3 \%$ of Niangaly [5] but above 8.33\% of Togo A [18]. Despite the high nature of anastomosis resections in our study $71.2 \%$, we found no significant difference (p0.05) in morbidity-mortality with that of the African series [8] [9].

Significant morbidity was observed (Table 3 ) when the Mannheim score was greater than 26 ( $p>0.05)$. This could be explained by the general poor condition of our patients. As reported in the Sanogo ZZ study [9] "patients are received in a state of physiological misery", linked mainly to the delay of management and the importance of peritoneal septicity observed in intraoperative findings. The average length of hospital stay of 12.2 days in this study is comparable to the 12.8 days of Allode AS [4]. On the other hand, it is lower than that of Ouédraogo S [17], Coulibaly Y [3], and Niangaly [5], who respectively found an average length of stay of 16.9 days, 17.12 days and 18.6 days. The hospital stay increases the cost of patient management.

\section{Conclusion}

Typhoid perforations are quite common in visceral surgery. They generate a lot of morbidities and mortalities in the surgical environment. However, in recent years we have seen a significant decrease in its prevalence since the extension of hand washing in our country.

\section{Limitations}

The limitations of this study were: the sample size which was small, the incompleted record of retrospective nature and the duration of study which was short.

\section{Conflicts of Interest}

The authors declare no conflicts of interest regarding the publication of this paper.

\section{References}

[1] Fattorusso, V. and Ritter, O. (2004) Vadémécum clinique. Du diagnostic au traitement 
$17^{\text {ème }}$ Edition, Elsevier-Masson, Amsterdam, 456-457.

[2] Kassegne, I., Sewa, E.V., Kanassoua, K.K., Alassani, F., Adabra, K., Amavi, A.K., et al. (2016) Diagnostic, Therapeutic and Prognostic Aspects of Typhoid Perforations of the Small Intestine in Dapaong, Togo. Médecine et Santé Tropicales, 26, 71-74. https://doi.org/10.1684/mst.2016.0544

[3] Coulibaly, Y., Togo, A., Keita, M., Diakité., A.A., Dembélé, B.T., Diakité, I., Kanté, L., et al. (2013) Peritonitis by Typhoid Perforation in Children: Evaluation of Morbidity and Mortality at the CHU Gabriel Touré. Mali Medical, 3, 24-27.

[4] Allode, A.S., Dossou, F.M., Hodonou, A.M., Séto, M., Gbessi, G.D., Sambo, B.T., et al. (2017) Non Traumatic Intestinal Perforation in the Regional Hospital Borgou of Benin: Epidemiological and Therapeutic Characteristics. International Surgery Journal, 4, 1376-1379. https://doi.org/10.18203/2349-2902.isj20171145

[5] Niangaly, A. (2019) Perforations iléales d'origine typhique au service de chirurgie générale de l'hôpital Somine Dolo de Mopti. Thèse Méd, FMOS.

[6] Allassani, F., Tchangai, B., Amavi, A.K., Adabra, K., Kassegne, I., Amouzou, E., et al. (2017) Etiological and Therapeutic Aspects of Acute Diffuse Non-Traumatic Peritonitis at the Sylvanus Olympio CHU. African Journals Online, 19, 1-2.

[7] Togola, B., Coulibaly, B., Traoré, D., Koîta, A., Ould, S., Ongoïba, N., et al. (2013) Peritonisis by Typhoid Ileal Perforation: Evolutionary Aspects in the Teeching Hospital of Bamako and Kati in Mali. Mali Medicine, 28, 1-5.

[8] Kambiré, J.L., Ouédrago, S. and Traoré, S.S. (2017) Result of the Management of Typhoid Ileal Perforations: About 29 Cases in Ouahigouya (Burkina Faso). Bulletin of the Ecstic Pathology Society, 110, 298-299. https://doi.org/10.1007/s13149-017-0579-5

[9] Sanogo, Z.Z., Sanogo, B., Koïta, A.K., Traoré, D., Camara, M., Traoré, S., et al. (2013) Thyphoid Ileal Perforations: Clinical and Therapeutic Aspects and Tropical Land. Mali Médical, 3, 5-9.

[10] Amadou, H., Abou, O., Amadou, Magagi, L., Amadou, M.A., Amadou, M. and Sani, R. (2016) Etiologies, Treatment of Acute Peritonitis at the National Hospital of Zinder: About 320 Patients. Revue Africaine de Chirurgie et Spécialités, 1, 12-18.

[11] Ouangré, E.M., Bonkougou, P.G., Sanou, A. and Traoré, S.S. (2014) Generalized Peritonitis in Rural Areas in Burkina Faso about 221 Cases. Revue Cames Sante, 1, 75-79.

[12] Coulibaly, M., Traoré, D., Togola, B., Sanogo, S., Bengaly, B., Kanté, A., Ouattara, D., et al. (2019) Perforation Digestive Non Traumatique à Koutiala : Aspects épidémio cliniques et therapeutiques. Mali Médical, 3, 20-23.

[13] Tourel, P. (2006) Perforations Digestives: New Diagnostic and Therapeutic Challenges. Continuing Medical Education. JFR, 427-433.

[14] Ayité, A., Dosseh, D.E., Katakoa, G., Tekou, H.A. and James, K. (2006) Surgical Treatment of Unique Non-Traumatic Perforations of the Small Intestine. Annales de Chirurgie, 131, 91-95. https://doi.org/10.1016/j.anchir.2005.11.008

[15] Ngo, N.B., Mouafo, T.F.F., Ngowe, M., Takongmo, S. and Sosso, MA. (2010) Surgical Treatment of Unique Non-Traumatic Perforations of the Small Intestine. Annales de Chirurgie, 131, 91-95.

[16] Vignon, K.C., Mehinto, D.K., Vignon, K.R., Mbele, R.I.I., Natta N’tchaa, N.H., Hounkpe E.J. and Koutoukou, M. (2016) Peptic Ulcer Perforations at the National Hospital and University Center (Cnhu) of Cotonou (Benin). European Scientific Journal, 12, 1857-7881 
[17] Ouédraogo, S., Ouangre, E. and Zida, M. (2017) Epidemiological, Clinical and Therapeutic Profiles of Ileal Perforations of Typhoid Origin in Rural Burkina Faso. Médecine et Santé Tropicales, 27, 67-70. https://doi.org/10.1684/mst.2017.0661

[18] Togo, A., Coulibaly, Y., Kanté, L., et al. (2009) Peritonitis by Typhoid Perforations at the Gabriel-Touré University Hospital in Bamako (Mali). Journal Africain d Hépato-Gastroentérologie, 3, Article No. 198.

https://doi.org/10.1007/s12157-009-0132-7 